\title{
An Investigation into Dynamic Conditional Correlation of Pakistan Stock Market with its Trade Partners - Under Covid- 19 Perspective
}

\author{
MS. HINA SHAHRUKH \\ Ph.D. Scholar, Department of Management Sciences, \\ COMSATS University Islamabad, \\ Email: hinas@hsco.pk \\ Tel: 00923018114232 \\ Dr. IMRAN ABBAS JADOON \\ Assistant Professor, Department of Management Sciences, \\ COMSATS University Islamabad, \\ Email: imran.jadoon@comsats.edu.pk \\ Tel: 00923328922474
}

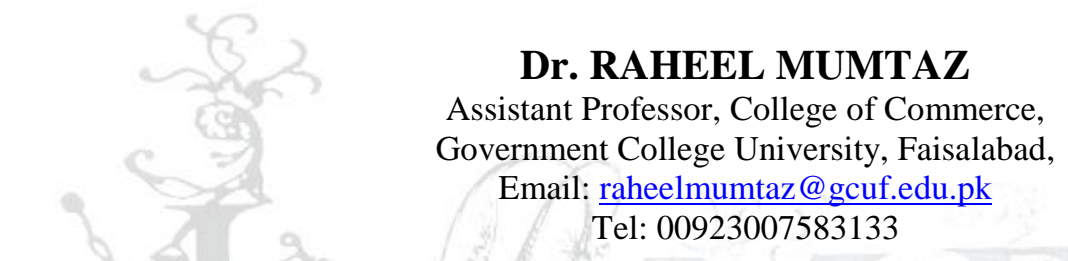

\begin{abstract}
This study investigates the financial linkage of Pakistan stock market with those of its three major trade partners i.e., China, UK and USA and the impact of ongoing global health crisis (Covid-19) on this linkage. A Dynamic Conditional Generalized Autoregressive Conditional Heteroscedasticity (DCCGARCH) approach was used to calculate dynamic correlation coefficient between the countries' stock markets by using the daily price data of MSCI indices spanning the period 1st January 2016 to 31 December 2019 (Pre COVID-19 period) and 1st January 2020 to 30th June 2020 (COVID-19 period). The empirical results of the study highlighted that the integration of Pakistan stock market with the sampled countries was relatively low before the COVID 19 pandemic - which indicated a positive sign for market participants to diversify their portfolios. However, after the pandemic breakout, the correlation among stock markets increased substantially, indicating the significant role played by the shock events in the transmission of financial contagion between different stock markets.
\end{abstract}

Keywords: Stock Market, Dynamic Conditions, Covid-19, Pakistan.

\section{Introduction}

Markowitz' Modern Portfolio Theory (MPT) and idea of Capital Asset Pricing Models (CAPM) postulated that the market participants are able to optimize their portfolio performance by apportioning the investment amount into different categories of financial assets that do not move together with any new event or market condition (Sharpe, 1964). This means that including least correlated or sometimes even negatively correlated assets in portfolio is particularly important for managing the financial risk and making a diversified portfolio. Subsequently, researchers extended the possibilities of CAPM and MPT to the 
international context and suggested that investors are able to reach at a higher efficient frontier if they include international assets in their portfolios (Solnik, 1977).

Over the periods, global stock markets have become more interlinked and the possibilities of trade \& financial linkages between the countries are considered to be the major determination of stock exchange integration (Xiao \& Dhesi, 2010). The global financial crises of 2008 attracted the researchers' attention towards the interconnectedness of financial markets, when the collapse of US stock market adversely affected the financial and stock markets of many countries from almost all parts of the world (Kao et al., 2019). This interconnectedness of financial markets was also evident during the Asian Crisis in 1997 and the terrorist attacks on World Trade Centre in 2001.

By the end of year 2019, World Health Organization officially notified about an outbreak of infectious disease (COVID 19) having its epicenter in Wuhan, China. It was described as an unknown type of pneumonia and its virus is transmitted from person to person. In January 2020, the first infection appeared outside of China. As of June 30, 2020, the number of cases exceeded 10 million and the number of deaths exceeded 500,000. As on January, 2021, the number of cases reaches to 90 million and number of deaths reaches to the 1.935 million (WHO, 2021).

February and March 2020 had been the worst months for global stock markets since 2008. Stock indices lost tens of percent, and experts began to say that the 11-year growth cycle since the last financial crisis has come to an end. Amid this pandemic, market participants redefined their perception about the future of the world economy. The restraining measures adopted by many countries has adversely affected almost all the industries including tourism, retail, trade, hotel and catering, entertainment etc. Most of the investors have started selling their shares in oil companies, airlines, consumer electronic and such other industries, with an anticipation of a decrease in revenue and future earnings. Stock exchanges of some leading countries also collapsed. During the months of February and March 2020, Italian stock exchange dropped by $29.8 \%$. Interestingly, the Chinese stock market started recovering gradually, while stock markets of all the other countries continued to fall.

\section{Problem Statement}

Numerous studies have already been carried out to explore the integration and correlation effect of different stock markets and assets markets, however, most of them were focused on the markets from developed countries. There is a lack of relevant literature in the context of emerging economies and more specifically for Pakistan Stock Market.

While taking into account the psychological and physical re-estimation of stock markets as to how they would turn into normality, the effects of recent global pandemic (COVID-19) need to be scrutinized, particularly because of ever-expanding technological advancements and the speedy flow of information. In previous pandemics, for instance, during the outbreak of 2003, research studies discussed that the daily returns of stock markets from infected countries showed greater co-movements and integrated relationship during the SARS period, as compared to the periods before SARS outbreak (Bhuyan et al., 2010). Similarly, the contagion effect of financial crises (2008-09) created both short- and long-term shocks in the European Stock Markets (Dewandaru et al., 2018).

Considering the dearth of the available literature in the context of Pakistan Stock Market, this study explores the dynamic linkages between the Pakistan stock market (PSX) with the stock indices of its major trade partners: United States of America (16\% of total exports), China (7.7\% of exports) and United Kingdom (7.3\% of export) before and during COVID-19 period. Since most of the earlier research studies were limited to investigating unconditional correlation, leptokurtosis, volatility clustering, and time-varying features; there is a need to use advanced econometric approaches to investigate the existence of conditional 
correlations between stock markets of Pakistan and its largest trading partners. Hence, this study attempts to explore the following research questions:

1. Is there any financial linkage between the Pakistan Stock Market and its major trade partners?

2. Has there been any effect of Covid-19 Pandemic on the financial linkage between Pakistan Stock Market and its major trade partners?

\section{Literature Review}

The increase in capital flow between countries due to globalization and technological innovation has resulted in proliferation of volatility transmission and co-movement of returns of global stock markets. This is because of certain implicit and explicit reasons as enlisted by (Harris \& Pisedtasalasai, 2006); some of these include sharing of information, technological advancements, borrowing from international markets, free trades, and foreign participation in local financial markets etc.

Apart from its effect on hedging strategies and portfolio diversification, stock market integration among different countries (both developed and developing ones) has certain benefits for establishing a stable world economy. It brings competition and improves the efficiency of domestic markets, by affecting the price levels and cost of capital (Caporale et al., 2019). The increased levels of capital inflows improve financial stability and stimulate economic growth.

International stock market correlation scrutinizes the financial structure of developing \& emerging economies around the globe, offering useful empirical outlook to the market linkages, price and return comovements, contagion effects of financial crises, and volatility spillovers (Mobarek \& Mollah, 2016). Furthermore, they claimed that the association between financial integration and market efficiency in the emerging or developing countries is an important determinant for effecting real economic growth.

Empirically, Grubel during 1968 investigated the potential benefits of diversifying the portfolio to international level and declared the superior performance of the portfolios that had both domestic and international assets from 11 different markets. His research findings were the confirmation of some previous studies wherein the analysis of market integration and co-movement involved both developed and emerging economies (Errunza, 1977; Levy \& Sarnat, 1970). The more recent literature on analyzing stock market cointegration has been geared by the internationalization of stock markets throughout the world. A variety of sophisticated models suggest that the upsurge in correlations of global stock returns have led to lower diversification advantages in the long run. However, the degree of market correlations changes with the passage of time (Forbes \& Rigobon, 2002; Jiang et al., 2017).

A lot of research has been done on the integral effects of the securities markets noted in various markets, both local and global. Researcher present a strong correlation and cointegration between the Australian securities market and that of the nations with which the country has trade linkages (Paramati, Roca, et al., 2016). This study uses multivariate regression models and "cointegration, asymmetric dynamic conditional correlation-generalized autoregressive conditional heteroscedasticity" (AGDCC-GARCH) to prove the existence and strength of this relation. Another group of researchers, on the same track, used ordinary least squire (OLS), dynamic OLS (DOLS), and fully modified OLS (FMOLS) models to ascertain whether such relationships exist between the markets of Australia and China, since they are known to have a significant amount of trade going on for quite some time.

Another study explained and identified how the size of the trade with other nations determined the strength of the correlation and cointegration (Paramati, Gupta, et al., 2016). After categorizing the trade volumes according to their size, it was noted that all categories were affected the same; therefore, size of the trade volume did not have any effect on the long-term correlation. Some researchers presented findings that the securities market of Australia was much less affected by those of the developing countries in comparison to 
already developed countries. During global events, such as a financial crisis, the relationship between these markets appears to have been more in sync, the highest being at the time of the GFC (when comparing post and pre GFC correlations).

The Asian countries have a strong bond among each other's stock markets (Vo, 2018). Whereas, the correlation in other macro-economic variables of two Asian nations (especially when they have recently undergone the industrialization stage) does not directly lead to the same effects in stock markets of respective nations (Dhanaraj et al., 2013). Their research showed that increasing or decreasing the level of trade does not affect their stock market integration too much. The same results are reported by (Vithessonthi \& Kumarasinghe, 2016) and covered 15 countries and twenty-eight years timespan. Another study presents the relation of the stock exchanges of 5 Asian countries with the stock exchange of Vietnam (Hoang Thuy Bich Nguyen \& Huynh Lam, 2017). Using fixed and random effects model, the research identified a positive correlation. Similar research on Malaysian markets by using "Autoregressive Distributed Lag" (ARDL) model over weekly data for a 16-year time period (B. A. Karim \& Majid, 2010), and using "Vector Error Correction Model" (VECM) and Granger causality tests over a 16-year time period, have presented the same results (M. zaini Karim \& Gee, 2006).

Correlations are essential inputs for financial decision making. Hedging and portfolio diversification require estimates of correlation between different financial assets or securities. If the correlation and volatilities between underlying assets are changing, the hedge ration needs to be adjusted to take into account the most recent information. Likewise, construction of an optimal portfolio and allocation of asset require information about the covariance of returns (Engle, 2002). For estimating the dependence, the simplest and traditional method is Pearson's Correlation, which measures the dependence of variables in multivariate normal distribution. However, this method has limitation because it is used to estimate the unconditional linear correlation (Embrechts et al., 2010).

Moreover, it has become well acknowledged that there is not only strong correlation between the returns of international financial markets, but the interconnectedness of their volatility is also time varying (Aslanidis et al., 2010). Hence, it is important to measure this stochastic interdependence structure among different stock markets.

Now the classical methodology for identifying such a stochastic relationship was proposed by R. Engle, who for the first time recorded a mathematical model of autoregression of conditional heteroskedasticity (ARCH). This model has been generalized (Bollerslev, 1986). So, the famous algorithm appeared GARCH $(\mathrm{p}, \mathrm{q})$, which allows us to abandon the assumption that the variance is independent of its previous values and take into account their autocorrelation.

Its undoubted advantage is the property quick response to any observed stock market changes and recovery the level of volatility after its strong fluctuations. Over the past twenty years have been developed numerous modifications to the base model ARCH and GARCH.

However, classic ARCH and GARCH models are one-dimensional, which makes their direct application in determining future structure multidimensional data, such as an asset portfolio, characterized by a certain level of risk. In this sense, multidimensional GARCH models (or short - MGARCH) are more preferred so how to identify the interdependencies between components of a risk portfolio and produce sensitivity analysis (Celik, 2012). Nevertheless, their practical application in some cases is connected with difficulties because it requires assess a large number of unknown model parameters.

The main idea of expanding univariate GARCH models to multidimensional ones is that the volatility of some assets affects the volatility of others and interacting assets may belong to different sectors of the economy. Multidimensional models generate more reliable and accurate estimates of volatility than single- 
dimensional models individually (Karolyi, 1995). Thus, it is possible to make effective decisions in the areas of risk management, forecasting, and portfolio formation.

Along with forecasting volatility, modeling the dynamics of correlations of income of financial instruments is one of the most demanded and studied problems of modern financial economics. For example, in a cost model financial asset (CAPM) and arbitration theory estimates (ART) using correlation in as a measure of the relationship between financial tools based on the assumption of multidimensional normal distribution of asset returns. In addition, an understanding of dynamic properties of market correlations and dependencies between financial flows is important for the correct assessment of the level of cointegration of international markets both for investment and increase forecast accuracy.

Therefore, simulation values of correlation and volatility is fundamental in the implementation of economic valuation activities. A development of forecast models' dynamics of correlations of financial returns tools adapted to the analysis of specific situations in the financial market, in current times is very relevant.

\section{Methodology}

\section{Data}

For analysis, daily closing price data of MSCI Index of Pakistan, China, UK and USA was collected from Yahoo Finance for the period from January 2016 to December 2019 with 1081 observations for each country. The selected indices, and their symbols are given in the table below:

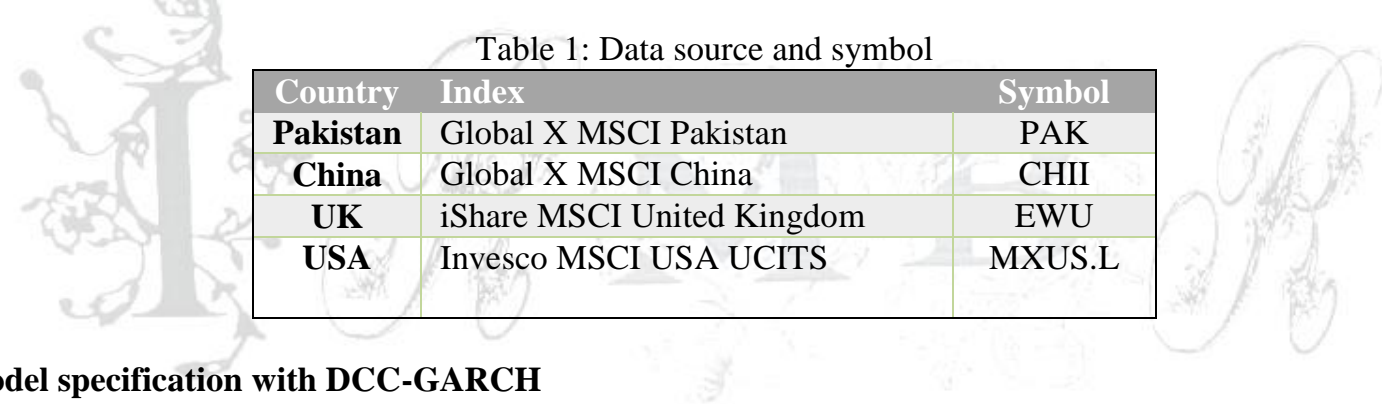

\section{Model specification with DCC-GARCH}

Information on the dynamics of correlation and covariance between the price indicators of financial assets is necessary when assessing investment risks and choosing portfolios. Even though unconditional correlations can be calculated, modeling the dynamics of conditional correlation is a rather complicated task. One of the models of conditional covariance and correlation is a model of generalized autoregressive conditional heteroskedasticity (GARCH). A generalization of the GARCH model to the multidimensional case was first proposed by Engle in 1982. This model requires an assessment of a large number of parameters and does not guarantee positive definiteness of the covariance matrix. In 1986, a multidimensional BEKK model was proposed, in which it is guaranteed positive definiteness of the covariance matrix. However, even canonical BEKK models need the measurement of many parameters, in view of which the practical application of these models is limited only to two-dimensional cases.

Bollerslev (1986) with constant correlation also solves the problem positive definiteness of the covariance matrix with a smaller number of parameters, since it does not take into account the dynamics of correlation. In mid 1980s, a multidimensional GARCH model was proposed that directly parameterizes the conditional correlation using its empirical estimation (Bauwens et al., 2006). A model was proposed in dynamic correlation (DCC), which also directly parameterizes conditional correlation and allows an efficient twostage parameter estimation algorithm. A comparative analysis of multidimensional models was made in GARCH. 
In most multidimensional GARCH models, conditional correlations are determined from the ratio of covariance and the product of the roots of conditional variations. A DCC-GARCH Model directly changes the parameterization correlation. The notation used for this model is:

$r^{-} t={ }^{-} \mu t+{ }^{-} \varepsilon t, \varepsilon^{-} t \mid \Omega t-1 \sim N\left({ }^{-} 0, H t\right)$,

where $r^{-} t$ is the vector of logarithmic increments of financial indicators, $\mu^{-} t$ is the vector that determines their average values, $\varepsilon^{-} t$ is the vector of residuals with the associated conditional covariance matrix $H t$ obtained on the basis of available on time point of information $\Omega t-1$. Further we will set $\mu^{-} t={ }^{-} 0$. We write the covariance matrix as:

$H t=D t R t D T t$

where $D t$ is the diagonal matrix, on the main diagonal of which are the roots of the variations, $R t$ is the correlation matrix. In the two-dimensional case, the correlation the matrix $R t$ has the following form:

$R t=\left(\begin{array}{lll}1 & \rho t \rho t & 1\end{array}\right)$

where $\rho t$ is the correlation between time series. The matrix $H t$ is positive definite if $R t$ is positive definite, which is guaranteed since $|\rho t|<1$. In order that $|\rho t|$ was less than one, we use following conversion:

$p t *=\frac{p t}{\sqrt{1+p t^{2}}}$

where $\rho t^{*}$ - limited correlation in the interval $(-1,1)$. This restriction allows the use of individual parameters in the equations for covariance, as well as allows the addition of additional parameters, providing a positive certainty of the covariance matrix. The model with variable correlation in the twodimensional case has the following form:

$$
\begin{gathered}
h_{11, t}=a_{11}+b_{11} \varepsilon_{1, t-1}^{2}+c_{11} h_{11, t-1}, \\
h_{22, t}=a_{22}+b_{22} \varepsilon_{2, t-1}^{2}+c_{22} h_{22, t-1}, \\
h_{12, t}=\rho_{t}^{*} \cdot \sqrt{h_{11, t} h_{22, t}}, \\
\rho_{t}^{*}=\frac{\rho_{t}}{\sqrt{1+\left(\rho_{t}\right)^{2}}}, \\
\rho_{t}=a_{12}+b_{12} \varepsilon_{1, t-1} \varepsilon_{2, t-1}+c_{12} \rho_{t-1} .
\end{gathered}
$$

A model with variable correlation lies in the class of models with dynamic correlation, because $\rho^{*} t$ is a random process. The covariance matrix is always positive definite. Each element of the covariance matrix determined by its own parameters, so that the assessment of the relevant parameters can be carried out independently, which allows to reduce dimension of the problem. The main advantage of this approach is the reduction in execution time of the optimization algorithm.

\section{Analysis: Pre-COVID 19}

Daily returns are calculated using the time series directory in R-programming. The formula for daily returns is:

$R t=\ln \left(\frac{P t}{P t-1}\right)$ 
Here $P t$ and $P t-1$ are the daily closing prices on today and yesterday, respectively. Charts of Closing price and daily return movements of all the indexes before the COVID-19 crisis is given as below:
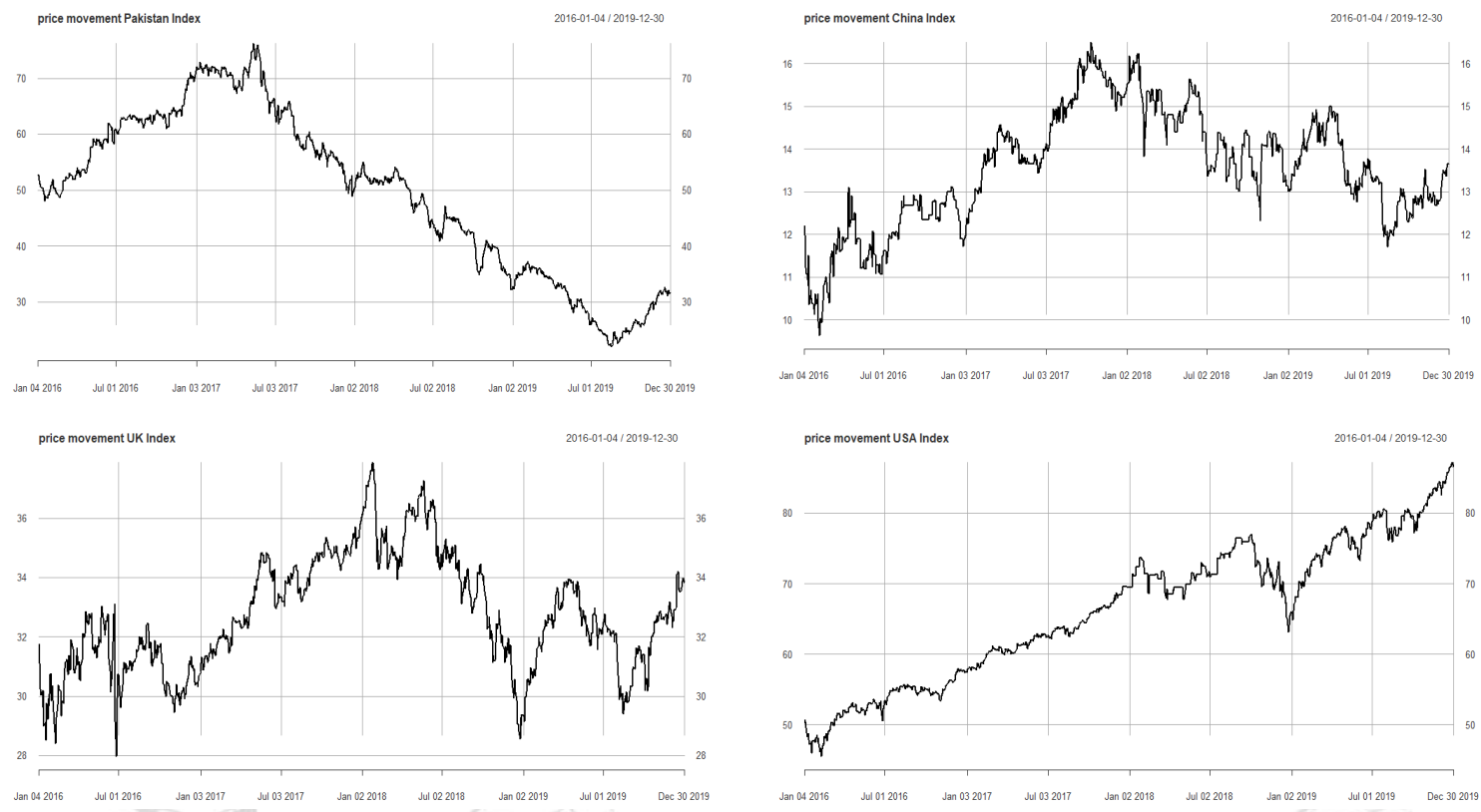

Figure 1: Price Movements of country-wise Indices

The above graphs represent a similar trend for Pakistan, China and UK indexes, where a highest price is achieved during 2017-18 and then dropped to extreme low values during 2019. However, USA index showed a steady price movement.
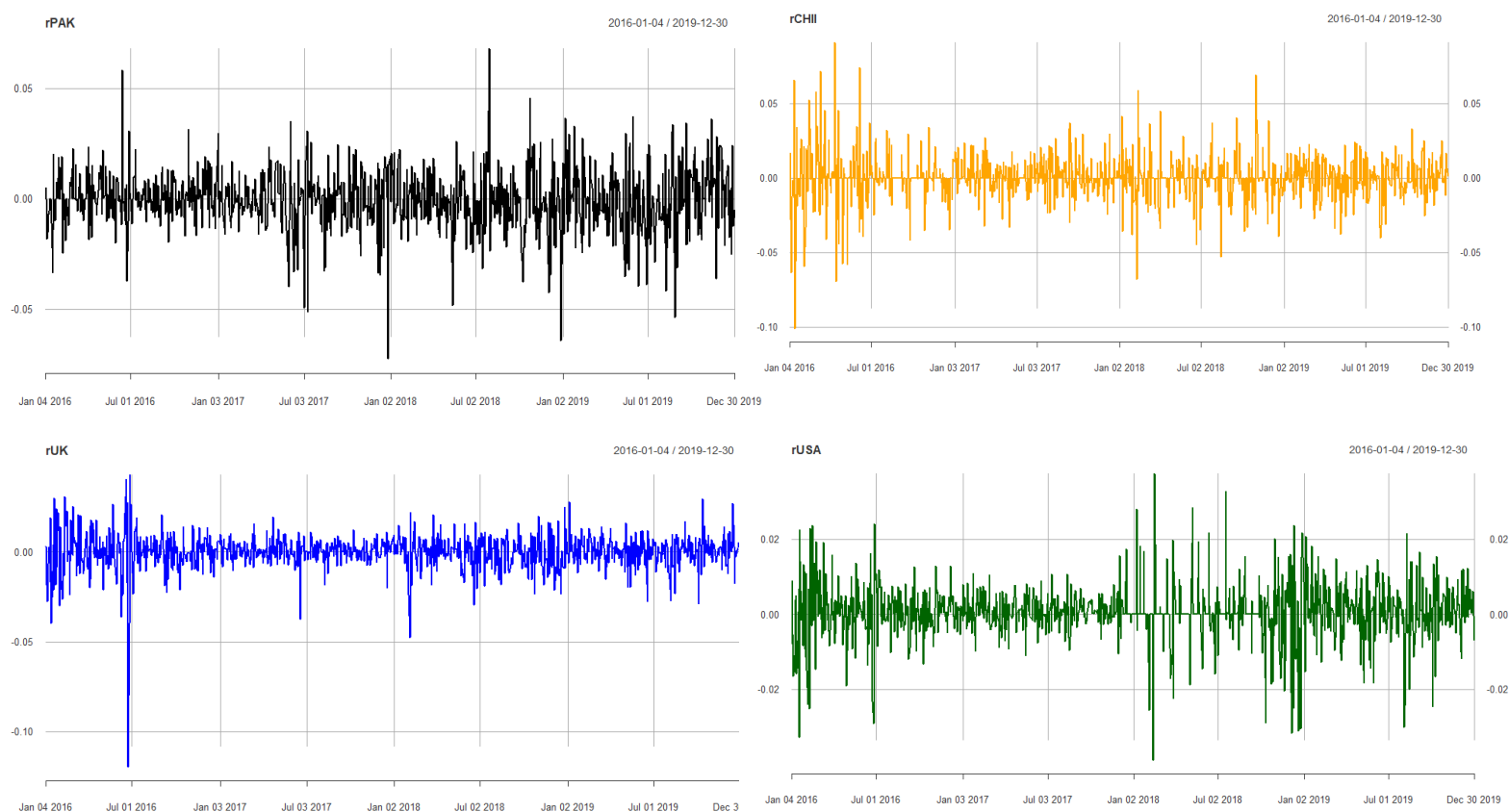

Figure 2: dynamics of daily equity indices 
They above graphs point to clustering of volatility, periods of high volatility followed by periods of relative tranquil. The cluster of extremely high volatility appeared during the first two quarters of 2016.

\section{Descriptive Statistics}

Descriptive statistics of the analyzed series of returns from January 2016 to December 2019 are given in table below:

Table 2: Descriptive Statistics of return series (Pre-COVID 19)

\begin{tabular}{|c|c|c|c|c|}
\hline & rPAK & rCHII & rUK & rUSA \\
\hline Mean & -0.04126 & 0.02183 & 0.01158 & 0.05596 \\
\hline Median & 0.000 & 0.000 & 0.06297 & 0.000 \\
\hline Maximum & 6.787 & 9.07563 & 4.28878 & 3.743 \\
\hline Minimum & -7.229 & -10.07819 & -11.96374 & -3.89192 \\
\hline Standard & 0.01366 & 0.015308 & 0.009976 & 0.007628 \\
Deviation & & & & \\
\hline Skewness & -0.25284 & -0.0464 & -1.930459 & -0.4252428 \\
\hline Kurtosis & 2.585122 & 6.558361 & 22.10313 & 4.169323 \\
\hline Jarque-Bera & 293 & 1812 & 21177 & 767 \\
\hline Probability & 0.0000 & 0.000 & 0.000 & 0.000 \\
\hline
\end{tabular}

USA index has the highest average return while Pakistan has the least average return. On the other hand, Pakistan has the $2^{\text {nd }}$ highest value of standard deviation of returns and USA has the least values. The return yields of all the countries have high excess rates that indicate the presence of weighted tails as well as negative coefficients skewness indicating that the daily returns have a longer left tail (extreme losses) than the right tail (marginal gains) (Arouri et al., 2010).

Jarque-Behr test stats are statistically significant; thus, the distribution of returns is not normal. This can also be visually represented by the histogram of return series.

Histogram of PPAK

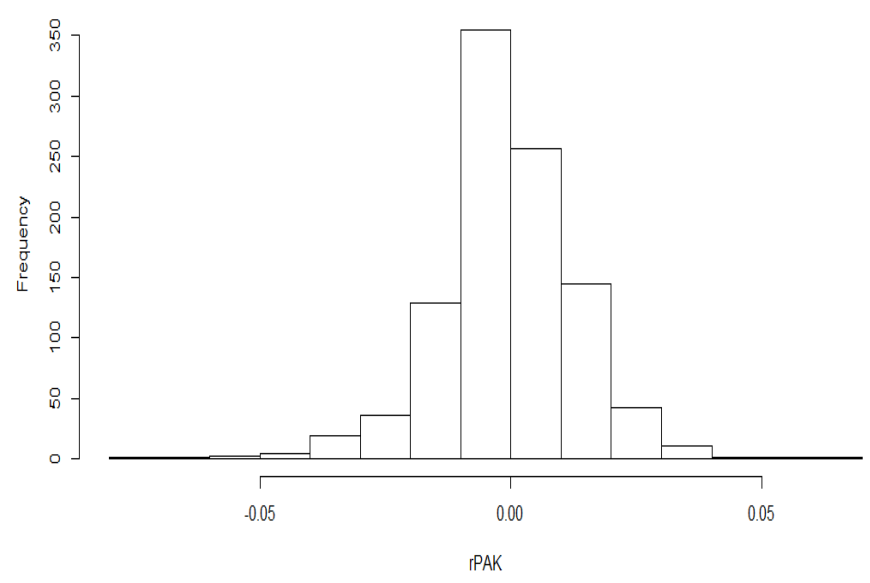

Histogram of rCHII

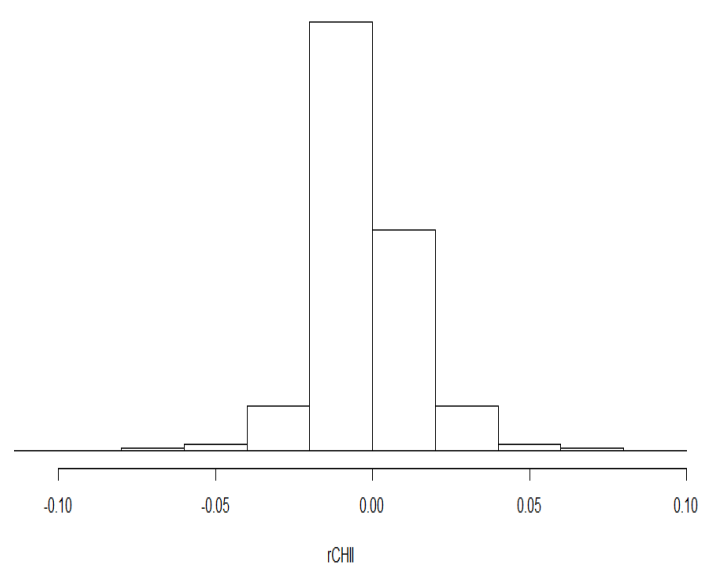



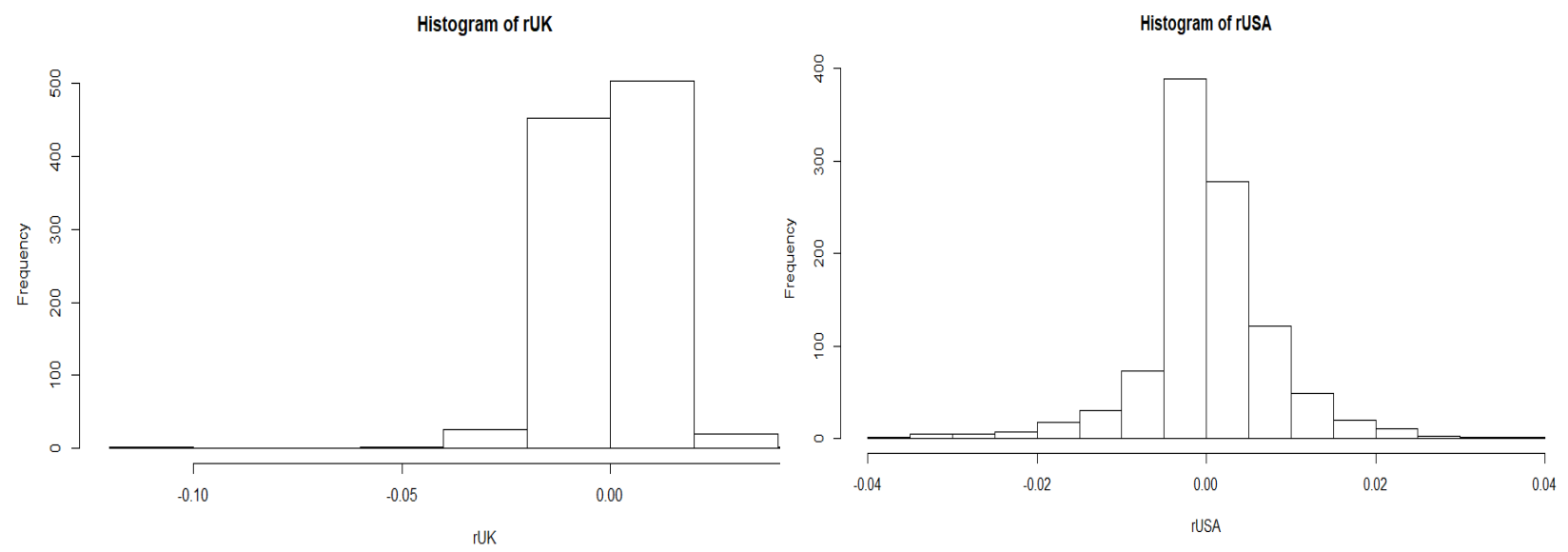

Figure 3: Histogram of return series

\section{Stationarity test of Time Series}

A stationary time series is independent of time i.e., it does not have a specific trend or seasonal effects. Different statistical modeling techniques has a prerequisite that the time series should be stationary in order to be effective. A stationary time series makes it easier to model.

\section{Augmented Dickey-Fuller test (ADF test)}

$\mathrm{ADF}$ test is one of the widely used test of stationarity of time. It is used to evaluate whether time series was first order trend stationary with null hypothesis that it had a unit root and was not stationary. The reason behind a single root test is that it establishes how much the time series is determined by the trend.

The null hypothesis (Ho) used for the ADF test is that the time series in non-stationary and it can be represented by a unit root, which indicates that the series has some time dependent structure. The alternative hypothesis (H1) against this null hypothesis shall be that the time series in stationary.

The interpretation of test shall be made by p-value. A p-value below the threshold value (e.g., $5 \%$ or $1 \%$ ) assumes that we fail to accept the null hypothesis (i.e., we can claim that timeseries is stationary), otherwise a p value beyond the threshold value indicates that we shall accept the null hypothesis (i.e., time value is non-stationary).

Unit Root ADF Test Results for daily returns are given in table below:

\begin{tabular}{|c|c|c|c|c|}
\multicolumn{5}{c}{ Table 3: ADF test results } \\
\hline Index & PAK & CHIII & UK & USA \\
\hline ADF & -21.96 & -24.693 & -22.181 & -23.412 \\
\hline p-value significance at & 0.01 & 0.01 & 0.01 & 0.01 \\
\hline Result & Stationary & Stationary & Stationary & Stationary \\
\hline
\end{tabular}

P-value for the return of country indices is less than 0.05 , we shall eject the null hypothesis (H0), and can claim that the data do not have a unit root and are stationary. 


\section{Weighted Ljung-Box Q series tests (on standardized residual)}

This is used to test the presence of autocorrelation in time series data. We have checked autocorrelation for 10-lag periods. The null hypothesis is - there is no serial auto correlation, while the alternative hypothesis indicates existence of serial autocorrelation. The results of Ljung-Box Q test at lag 1 are:

Table 4: Ljung-Box Q series test results

\begin{tabular}{|c|c|c|c|c|}
\hline Index & PAK & CHII & UK & USA \\
\hline Q Test & 0.3573 & 0.02953 & 0.8032 & 0.3156 \\
\hline $\begin{array}{c}\text { p-value } \\
\text { significance at }\end{array}$ & 0.55 & 0.8636 & 0.3701 & 0.5743 \\
\hline Result & $\begin{array}{c}\text { No } \\
\text { autocorrelation }\end{array}$ & $\begin{array}{c}\text { No } \\
\text { autocorrelation }\end{array}$ & $\begin{array}{c}\text { No } \\
\text { autocorrelation }\end{array}$ & $\begin{array}{c}\text { No } \\
\text { autocorrelation }\end{array}$ \\
\hline
\end{tabular}

\section{Weighted ARCH LM Tests}

This is used or testing the null hypothesis whether the series adequately fits the ARCH Model. The results are insignificant which indicates acceptance of null hypothesis and thus our series is suitable for GARCH Model.

Table 5: ARCH LM Tests

\begin{tabular}{|c|c|c|c|c|}
\hline Index & PAK & CHII & UK & USA \\
\hline Statistics & 0.7151 & 0.3401 & 2.894 & 0.3908 \\
\hline Shape & 0.500 & 0.500 & 0.500 & 0.5000 \\
\hline Scales & 2.000 & 2.000 & 2.000 & 2.000 \\
\hline P-Value & 0.3977 & 0.5597 & 0.08893 & 0.5319 \\
\hline
\end{tabular}

\section{Autocorrelation Function (ACF) charts}

The graphical representation of all the return series for no autocorrelation can be made through ACF and PACF charts.
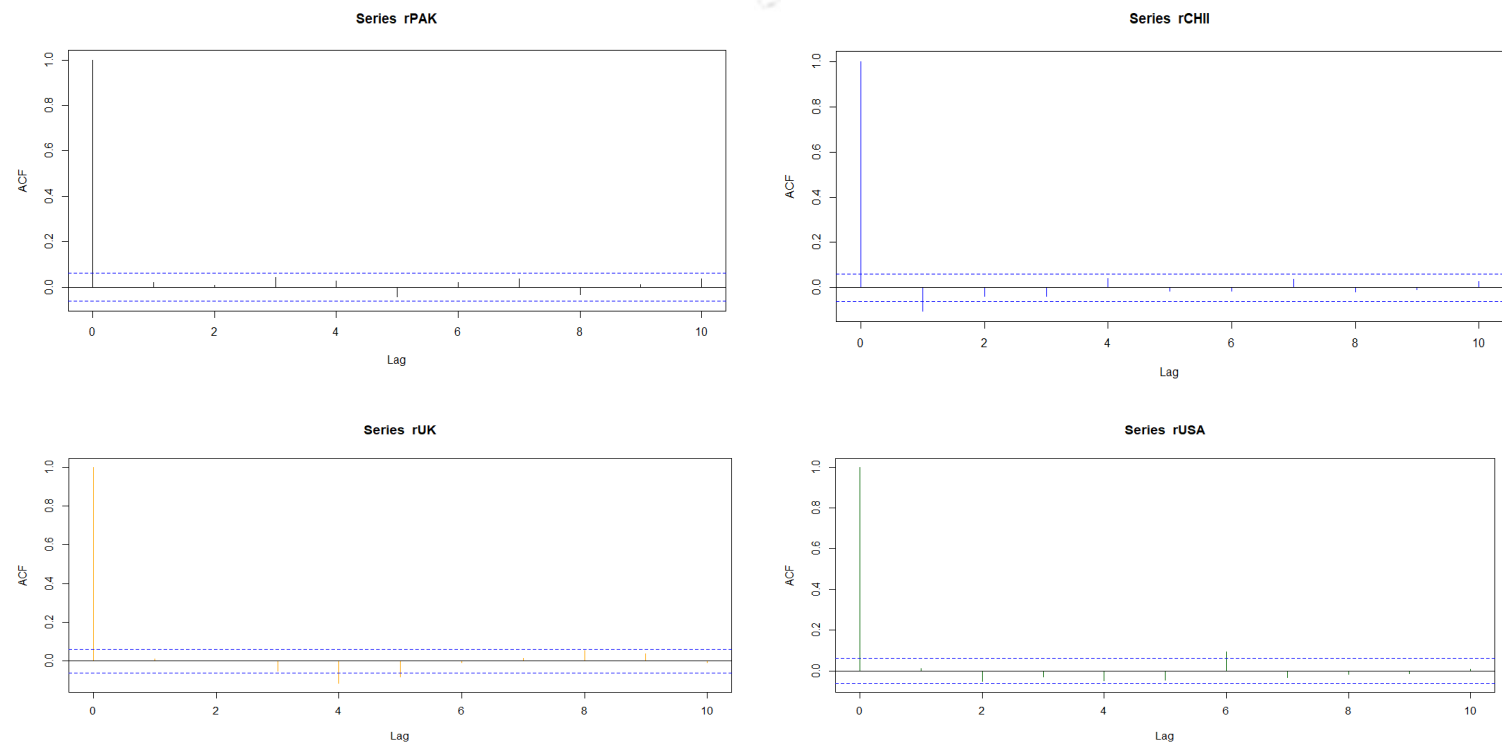

Figure 4: ACF Charts of selected series 


\section{Unconditional Correlation}

The unconditional correlation of daily return of Pakistan index with that of its trade partners is showing positive numbers as given below:

Table No: 6

\begin{tabular}{|ccccc|}
\hline Countries & Pakistan & China & UK & USA \\
\hline Pakistan & 1.00000000 & 0.07813844 & 0.17567379 & 0.08573633 \\
China & 0.07813844 & 1.00000000 & 0.30777381 & 0.17650595 \\
UK & 0.17567379 & 0.30777381 & 1.00000000 & 0.45250899 \\
USA & 0.08573633 & 0.17650595 & 0.45250899 & 1.00000000 \\
\hline
\end{tabular}

The results showed positive correlation of stock returns of all the countries where the relationship ranged from $7 \%$ to $45 \%$. The highest correlation was found between UK and USA. China and UK also have a significant correlation of $30.77 \%$. This indicates that the correlation between the developed countries is higher than the correlation with emerging economies. This can make Pakistan a worthy destination for portfolio diversification and risk management. However, Pearson's correlation can only provide the average correlation over the whole time period under study. In order to evaluate the variation in the correlations over the period, we shall employ Dynamic conditional correlation model (DCC-GARCH).

\section{Multivariate GARCH Model}

For a suitable GARCH model, it is important to consider the specification of MGARCH models. On one side, it must be adaptable enough to reveal the dynamics of conditional variances and covariances. While on the other side, with the number of parameters of the MGARCH model, its dimension rapidly increases, and the evaluation and interpretation of model parameters should be as simple as possible. However, simplifying the model can reduce not only the number of parameters, but also its effectiveness. Therefore, when developing a model, it is important to find a balance between dropping some of the parameters and maintaining the content component of MGARCH. We have used specifications of GARCH $(1,1)$ with mean model of ARFIMA $(1,0,1)$ which gives first-order autoregressive model with 1 Lag. Multi-fit GARCH Model with optimal parameters for all the return series are given as under.

Table No 7: Time Varying Conditional Correlation

\begin{tabular}{|c|c|c|c|c|c|c|c|c|}
\hline & \multicolumn{2}{|l|}{ Pakistan } & \multicolumn{2}{|l|}{ China } & \multicolumn{2}{|l|}{ UK } & \multicolumn{2}{|l|}{ USA } \\
\hline Variable & Coefficient & $\begin{array}{l}\text { Std. } \\
\text { Error }\end{array}$ & Coefficient & Std. Error & Coefficient & $\begin{array}{l}\text { Std. } \\
\text { Error }\end{array}$ & Coefficient & $\begin{array}{l}\text { Std. } \\
\text { Error }\end{array}$ \\
\hline$\alpha(0,1)$ & $-0.000293 *$ & 0.000156 & 0.000343 & 0.000584 & $0.000393 *$ & 0.000231 & 0.001733 *** & 0.000373 \\
\hline$\alpha(0,2)$ & $0.993766 * * *$ & 0.005127 & 0.389989 & 0.462746 & $\begin{array}{l}- \\
0.597504 * * *\end{array}$ & 0.140257 & $0.748891 * * *$ & 0.089651 \\
\hline$\alpha(1,1)$ & - $0.982432 * * *$ & 0.000108 & -0.481141 & 0.342421 & $0.569267 * * *$ & 0.139774 & $\overline{-}-781148 * * *$ & 0.082857 \\
\hline Omega & $0.000009 * * *$ & 0.000001 & 0.000003 & 0.000313 & $0.00007 * * *$ & 0.00002 & $0.000022 * * *$ & 0.00008 \\
\hline Alpha1 & $0.084175^{* * *}$ & 0.009486 & 0.034974 & 0.489761 & $0.219162 * * *$ & 0.037096 & $0.154836^{* * * *}$ & 0.045249 \\
\hline Beta1 & $0.871006^{* * *}$ & 0.014606 & $0.947874 * *$ & 0.464276 & $0.724157 * * *$ & 0.045670 & $0.749244 * * *$ & 0.06933 \\
\hline Dec $\alpha 1$ & $0.033593 * * *$ & 0.010598 & & & & & & \\
\hline $\operatorname{Dcc} \beta 1$ & $0.826581 * * *$ & 0.081019 & & & & & & \\
\hline
\end{tabular}


For all the countries, the value of $\alpha+\beta$ exceeds 0.9 , which allows us to conclude that there is a pronounced GARCH effect. All model parameters are significant at $10 \%$ (estimated with results obtained through univariate GARCH analysis of all the countries).

The results are consistent with the Engle's theory. Dcc $\alpha 1$ is close to zero while Dec $\beta 1$ is greater than zero. The sum of both of these values is less than 1 . The conditional correlational matrix of under the DCC fit model is given as below:

Table No: 8

\begin{tabular}{|ccccc|}
\hline Countries & Pakistan & China & UK & USA \\
\hline Pakistan & 1.00000000 & 0.1105396 & 0.1391120 & 0.08395342 \\
China & 0.11053959 & 1.0000000 & 0.3042024 & 0.13132314 \\
UK & 0.13911204 & 0.3042024 & 1.0000000 & 0.38829355 \\
USA & 0.08395342 & 0.1313231 & 0.3882935 & 1.00000000 \\
\hline
\end{tabular}

Just like Pearson's correlation, the time varying correlation under DCC model also shows positive relationship between the countries. However, there is relatively lower correlation between Pakistan's stocks return as compared to the rest of the other trade partners. The highest degree of correlation exists between UK and USA followed by UK and China. This is aligned with the findings of (Asgharian et al., 2018), wherein positive correlation was found between the financial assets of UK and USA. Thus, in comparison with other trade partners, Pakistan appears less integrated with the international stock markets, which can be a good sign for investors.
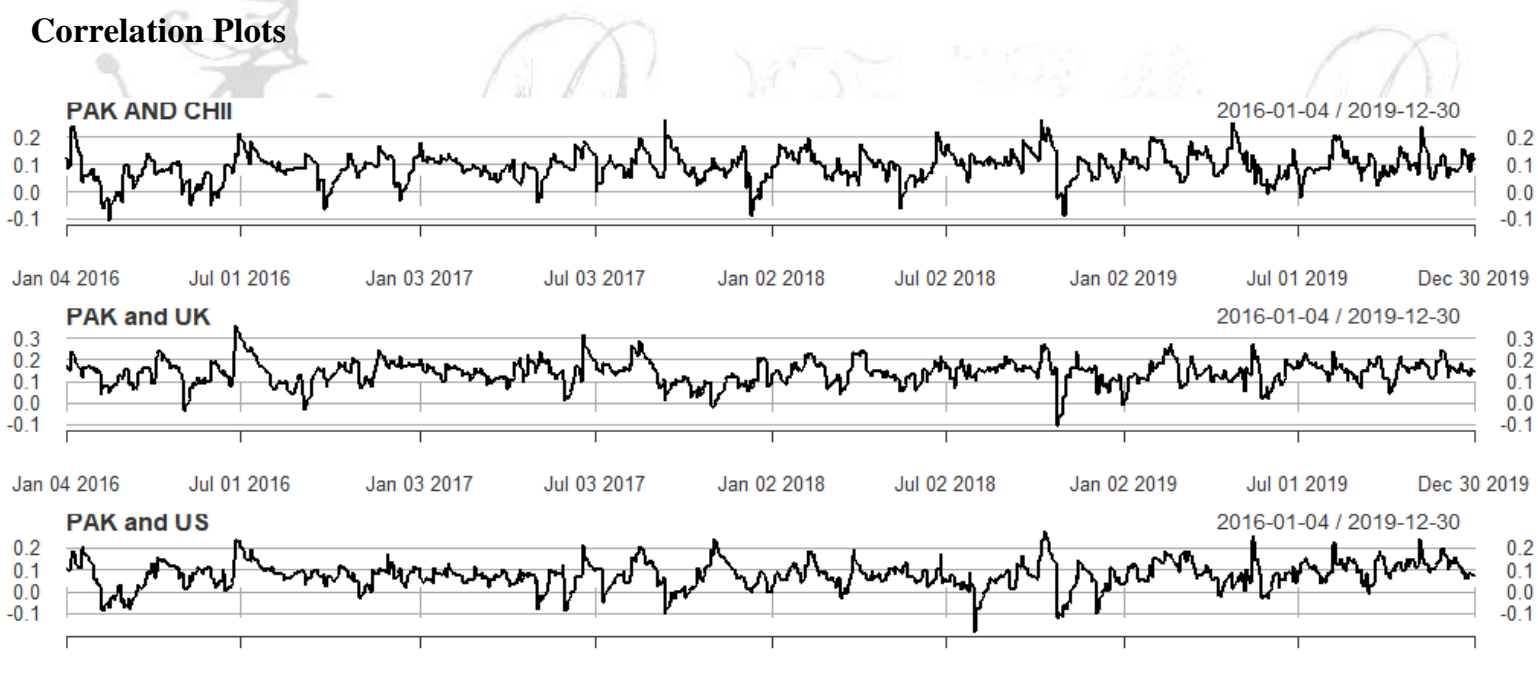

Jan 042016 Jul $012016 \quad$ Jan $032017 \quad$ Jul $032017 \quad$ Jan $022018 \quad$ Jul $022018 \quad$ Jan $022019 \quad$ Jul $012019 \quad$ Dec 302019

Above presented correlation plots show periodic co-movements of Pakistan stock index with those of its major trade partners. Most of the values lie between -0.1 to 0.2 , which shows that there is relatively low correlation between the Pakistan stock market and the developed economies. Moreover, there has been a mean reversion effect between the two series after some time.

\section{Forecast}

A 10-days' correlation forecast also shows similar pattern. 


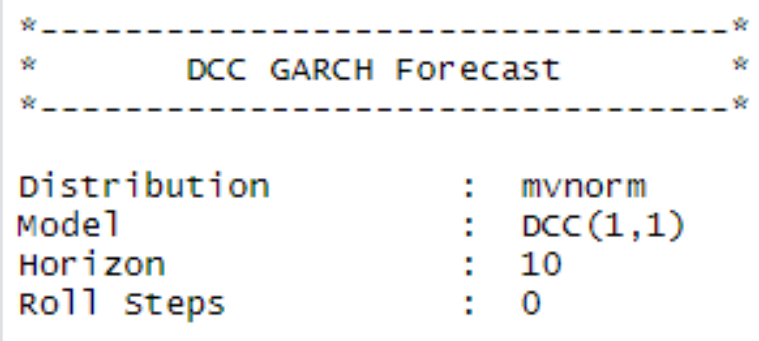

0-rol1 forecast:

First 2 correlation Forecasts , 1

$[, 1] \quad[, 2] \quad[, 3] \quad[, 4]$

$\begin{array}{llllll}{[1,]} & 1.00000 & 0.1057 & 0.1486 & 0.09978\end{array}$

$\left[\begin{array}{llllll}{[2,]} & 0.10566 & 1.0000 & 0.2965 & 0.12761\end{array}\right.$

$\left[\begin{array}{llllll}{[3,]} & 0.14857 & 0.2965 & 1.0000 & 0.41315\end{array}\right.$

$\left[\begin{array}{llllll}{[4,]} & 0.09978 & 0.1276 & 0.4131 & 1.00000\end{array}\right.$

$, \quad, 2$

\section{$[, 1] \quad[, 2] \quad[, 3] \quad[, 4]$}

$\left[\begin{array}{llllll}{[1,]} & 1.00000 & 0.1037 & 0.1476 & 0.09654\end{array}\right.$

$\left[\begin{array}{llllll}{[2,]} & 0.10370 & 1.0000 & 0.2965 & 0.13461\end{array}\right.$

$\left[\begin{array}{llllll}3,] & 0.14757 & 0.2965 & 1.0000 & 0.41403\end{array}\right.$

$\left[\begin{array}{llllll}4,] & 0.09654 & 0.1346 & 0.4140 & 1.00000\end{array}\right.$
Last 2 correlation Forecasts

, 1

$$
[, 1] \quad[, 2] \quad[, 3] \quad[, 4]
$$

$\left[\begin{array}{lllll}1,] & 1.00000 & 0.09583 & 0.1436 & 0.08357\end{array}\right.$

$[2] \quad 0.095831 .00000 \quad 0.2966 \quad$,

$\left[\begin{array}{lllllll}{[3,]} & 0.14357 & 0.29660 & 1.0000 & 0.41758\end{array}\right.$

$\left[\begin{array}{llllll}4,] & 0.08357 & 0.16266 & 0.4176 & 1.00000\end{array}\right.$

, 2

$\begin{array}{rrrrr} & {[, 1]} & {[, 2]} & {[, 3]} & {[, 4]} \\ {[1,]} & 1.00000 & 0.09525 & 0.1433 & 0.0826 \\ {[2,]} & 0.09525 & 1.00000 & 0.2966 & 0.1648 \\ {[3,]} & 0.14327 & 0.29661 & 1.0000 & 0.4178 \\ {[4,]} & 0.08260 & 0.16476 & 0.4178 & 1.0000\end{array}$

\section{Analysis - During COVID-19}

The first COVID case in Pakistan appeared in February 26, 2020 (WHO, 2020). Thus, for analysis of dynamic correlation, data of Pakistan and its three major trade partners was taken from January 01, 2020 to June 30, 2020.

\section{Price and return movements}

The price and return movements of the selected indices during the 6 months of pandemic are given below. All the stock indexes showed similar trend, when the stock prices reached to an extreme low in March 2020 .
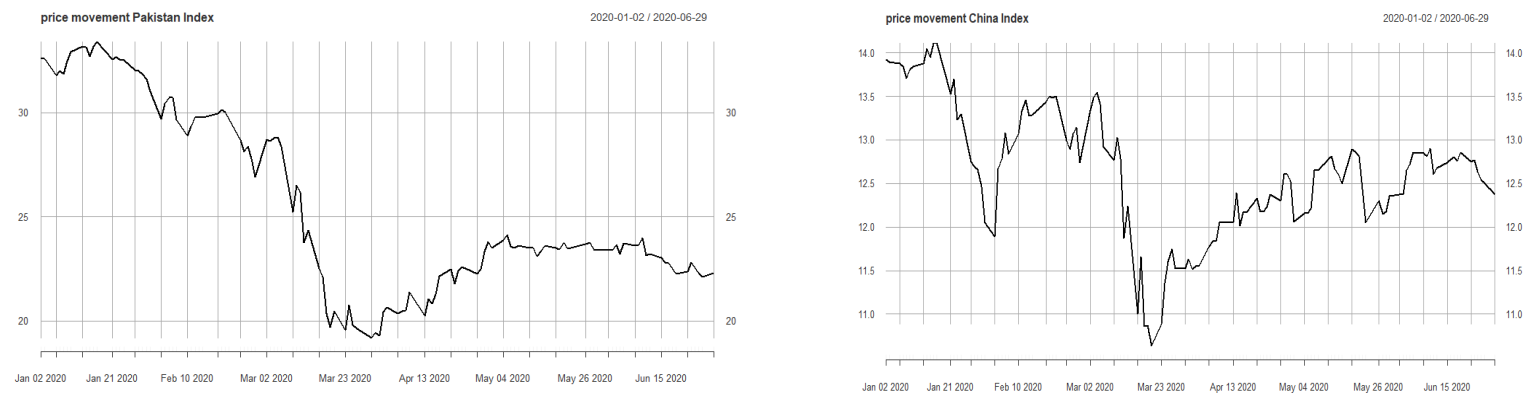

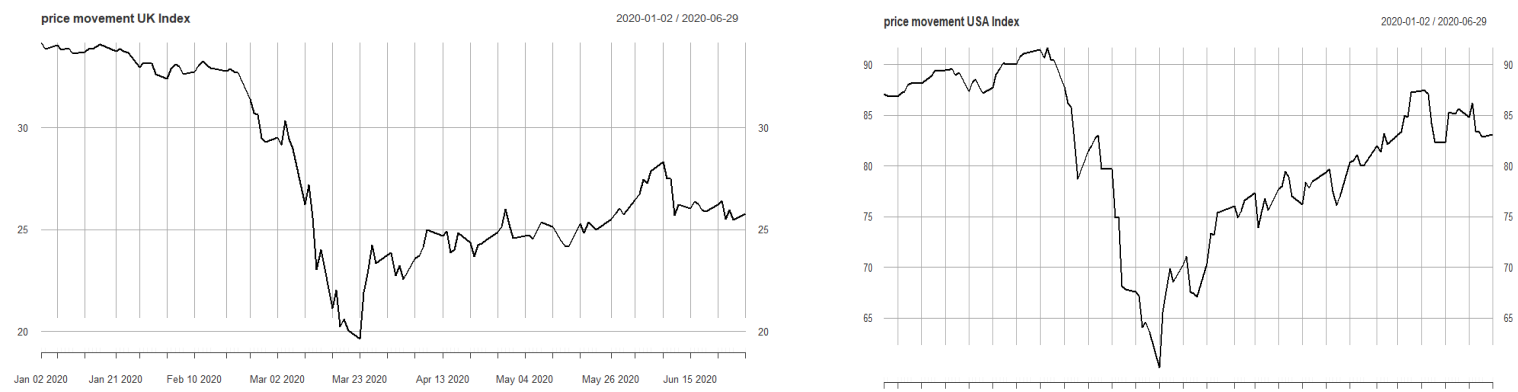

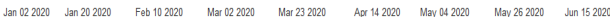

Similarly, the mid of March 2020 showed patterns of volatility clustering for all the four economies.

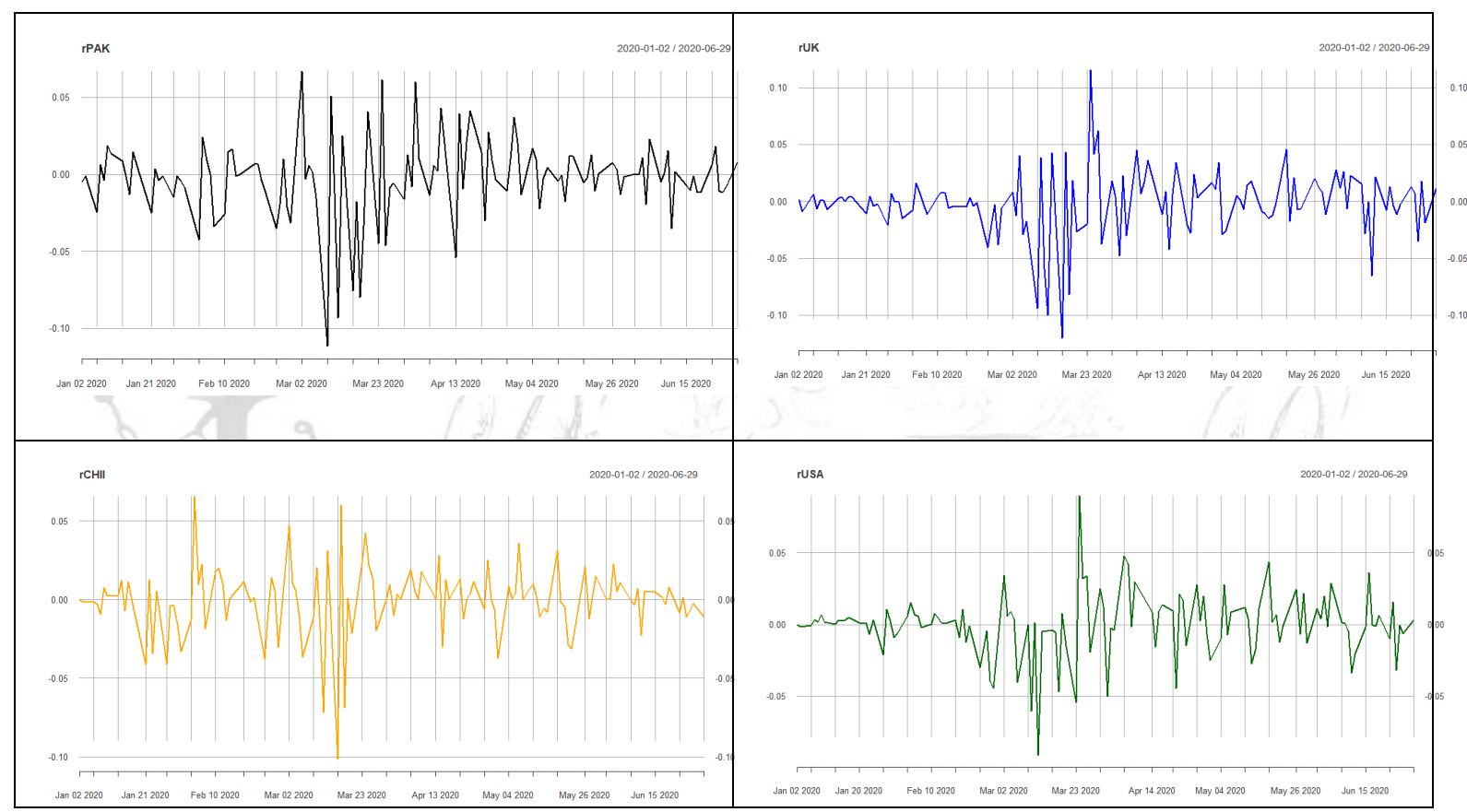

\section{Descriptive Statistics - During COVID 19}

Descriptive statistics of the analyzed series of returns for COVID-19 period are given in table below.

Table 9: Descriptive statistics of return series during COVID 19

\begin{tabular}{|c|c|c|c|c|}
\hline & $\mathrm{AK}$ & $\mathrm{rCHIII}$ & rUK & rUSA \\
\hline Mean & -0.2759 & -0.07001 & -0.18100 & -0.01236 \\
\hline Median & -0.1239 & 0.000 & -0.03014 & 0.10037 \\
\hline Maximum & 6.6865 & 6.56014 & 11.54629 & 8.95 \\
\hline Minimum & -11.1268 & -10.13072 & -11.999001 & -9.072 \\
\hline Standard Deviation & 0.02635 & 0.02234267 & 0.0298407 & 0.0224952 \\
\hline Skewness & -0.8166296 & -0.8731823 & -0.6191018 & -0.3454755 \\
\hline Kurtosis & 3.310894 & 3.981582 & 4.024653 & 3.441035 \\
\hline Jarque-Bera & 74.338 & 102.81 & 96.642 & 67.501 \\
\hline Probability & 0.0000 & 0.000 & 0.000 & 0.000 \\
\hline
\end{tabular}


Unconditional correlation during COVID-19

Table No: 10

\begin{tabular}{|ccccc|}
\hline Countries & Pakistan & China & UK & USA \\
\hline Pakistan & 1.0000000 & 0.5355903 & 0.6143977 & 0.1582371 \\
China & 0.5355903 & 1.0000000 & 0.6854264 & 0.2759947 \\
UK & 0.6143977 & 0.6854264 & 1.0000000 & 0.3524419 \\
USA & 0.1582371 & 0.2759947 & 0.3524419 & 1.0000000 \\
\hline
\end{tabular}

Unconditional correlation of Pakistan Stock Market with China, UK and USA is quite higher as compared to the pre-COVID 19 period.

\section{M-GARCH}

The results of GARCH model fit with optimal parameters are given below:

\section{Dynamic Conditional Correlation results}

Table No: 11

\begin{tabular}{|c|c|c|c|c|c|c|c|c|}
\hline & \multicolumn{2}{|l|}{ Pakistan } & \multicolumn{2}{l|}{ China } & UK & USA \\
\hline Variable & Coefficient & $\begin{array}{c}\text { Std. } \\
\text { Error }\end{array}$ & Coefficient & $\begin{array}{c}\text { Std. } \\
\text { Error }\end{array}$ & Coefficient & Std. Error & Coefficient & Std. Error \\
\hline$\alpha(0,1)$ & -0.0014323 & 0.001367 & 0.000260 & 0.001491 & -0.000607 & 0.001504 & 0.000877 & 0.001128 \\
\hline$\alpha(0,2)$ & 0.058583 & 0.270088 & $-0.618244^{* * *}$ & 0.118818 & $0.544685^{* * *}$ & 0.174939 & $-0.57985^{* * *}$ & 0.203317 \\
\hline$\alpha(1,1)$ & -0.194604 & 0.258815 & $0.439946^{* * *}$ & 0.119122 & $0.387196^{* * *}$ & 0.142016 & $0.500105^{* * *}$ & 0.174806 \\
\hline Omega & 0.000016 & 0.00021 & $0.000055^{*}$ & 0.000033 & 0.000034 & 0.000022 & 0.000014 & 0.000011 \\
\hline Alpha1 & $0.207165^{*}$ & 0.118357 & $0.216384 * *$ & 0.100783 & $0.272316^{* * *}$ & 0.108202 & $0.256534^{* * *}$ & 0.105771 \\
\hline Beta1 & $0.791835 * * *$ & 0.034618 & $0.678178^{* * *}$ & 0.088230 & $0.722445^{* * * *}$ & 0.057414 & $0.742466^{* * *}$ & 0.064254 \\
\hline Dcc $\alpha 1$ & 0.053507 & & & & & & & \\
\hline Dcc $\beta 1$ & 0.484635 & & & & & & & \\
\hline
\end{tabular}

Most of the coefficients are significant at $* 10 \%, * * 5 \%$ or $* * * 1 \%$.

Conditional Correlation Matrix

Table No: 12

\begin{tabular}{|ccccc|}
\hline Countries & Pakistan & China & UK & USA \\
\hline Pakistan & 1.0000000 & & & \\
China & 0.5080128 & 1.0000000 & & \\
UK & 0.5902379 & 0.6124342 & 1.0000000 & 0.4106516 \\
USA & 0.1954849 & 0.2914380 & 0.4106516 & 1.00000000 \\
\hline
\end{tabular}



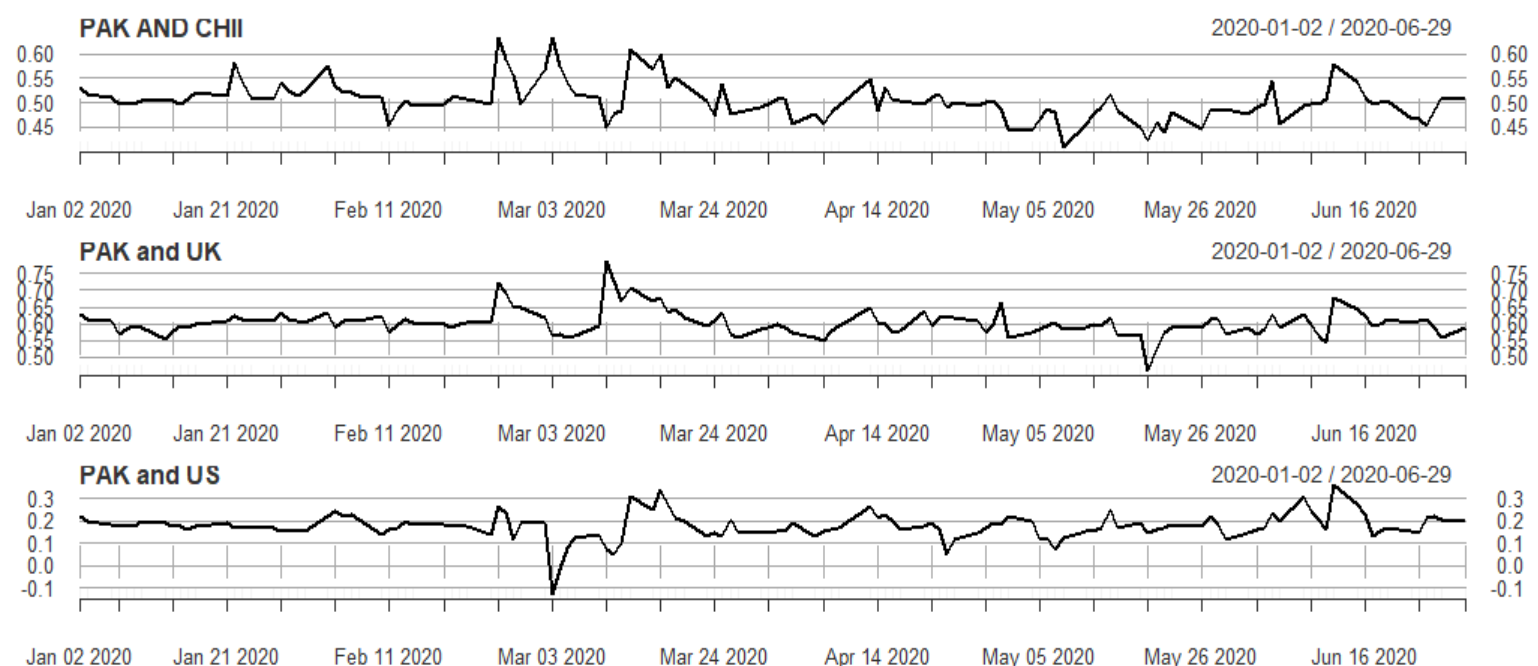

Figure 5: Conditional correlation chart

Just like un-conditional correlation, the conditional correlation of Pakistan stock index with the indexes of other three countries, has increased to a greater scale with the maximum correlation being observed with UK stock index, followed by China and then USA. Particularly with UK and China, the correlation values range from 0.45 to 0.65 which is quite large as compared to the pre-COVID period when the correlation values moved from -0.1 to 0.2 with reversion to their mean values after some time. This means that the comovement of stock returns of PSX and stock exchanges of selected trade partners of Pakistan showed weaker linkages from 2016 till 2019, and it increased significantly during the COVID-19 period. This tends to be an indicator of the vulnerability of the Pakistan Stock Market against the transmitted idiosyncratic shocks. The results are aligned with the previous studies which found the higher degree of association and interdependence between different stock markets and financial markets during and after the financial crisis of 2008 (Caporale et al., 2019; Kim et al., 2015; Naoui, 2010). Another researcher noticed a mean shift in the estimated DCC during late 2007 i.e., start of global financial crisis, and referred the findings as financial contagion from US to Asian Markets (Yiu et al., 2010). Similar behavior is being observed during the COVID-19 period, where just like the global financial crisis, a spike in conditional correlation was detected by different researchers (Akhtaruzzaman et al., 2020; Corbet et al., 2020; Günay, 2020). The results shall be valuable for regulators and policy makers in exploring the economic impact of the pandemic as well as the investors in diversifying their portfolio and managing their financial risk particularly during the shock events.

\section{Conclusion}

Correlation plays an important role in portfolio optimization. The lower the correlation of portfolio components, the more profit from diversification is manifested with reduced investment risks without a significant reduction in the profitability of the whole portfolio. Thus, when forming an investment portfolio, one should choose stocks from different classes, the prices of which are independent of each other, or which react differently to the same factor. That is why researchers are interested in finding the correlation effects of different asset market within country and cross country.

The integration of financial markets, volatility transmission, co-movement of indices and the extent of correlation between international financial markets performs a significant role in financial decisions making of the investors with regard to portfolio diversification or hedging their financial assets (Workman, 2020). For instance, a greater value of correlation between international markets may decrease the chances 
to diversify portfolio by taking into international assets, which consequently forces the market participants to look for other independent securities or assets to construct an optimal portfolio. Lately, there has been a higher level of stock market integration between developed economies and that is why, the investors have shifted their attention towards emerging economies for the purpose of diversifying their portfolios.

This paper gives some insights on the existence of correlation and contagious effect between the stock market of Pakistan (an emerging economy) with its three major trade partners (China, UK and USA). For this purpose, DCC-GARCH model was applied on the MSCI data from two different time-periods. First range is from January 01, 2016 to December 31, 2019 (Pre-COVID 19 period) and the other window ranges from January 01, 2020 to June 30, 2016 (COVID-19 Period). Before the pandemic, the result showed positive yet weak form of conditional correlation between Pakistan stock market and the other three stock indices, which makes Pakistan a worthy destination for portfolio diversification and hedging. However, during COVID-19 period, Pakistan stock market experienced significant increase in conditional correlations with the stock returns of China and UK. This change in correlation between international stock markets and the effect of a major crisis on the financial linkages may be of interest to investors, policymakers, regulators, and other market participants.

\section{References}

Akhtaruzzaman, M., Boubaker, S., \& Sensoy, A. (2020). Financial Contagion During COVID-19 Crisis (SSRN Scholarly Paper ID 3584898). Social Science Research Network. https://doi.org/10.2139/ssrn.3584898

Arouri, M. E. H., Jawadi, F., \& Nguyen, D. K. (2010). The Dynamics of Emerging Stock MarketsEmpirical Assessments and Implications.

Asgharian, H., Christiansen, C., \& Hou, A. J. (2018). Economic Policy Uncertainty and Long-Run Stock Market Volatility and Correlation. SSRN Electronic Journal. https://doi.org/10.2139/ssrn.3146924

Aslanidis, N., Osborn, D. R., \& Sensier, M. (2010). Co-movements between US and UK stock prices: The role of time-varying conditional correlations. International Journal of Finance and Economics, 15(4), 366-380. https://doi.org/10.1002/ijfe.402

Bauwens, L., Laurent, S., \& Rombouts, J. V. K. (2006). Multivariate GARCH models: A survey. In Journal of Applied Econometrics (Vol. 21, Issue 1, pp. 79-109). https://doi.org/10.1002/jae.842

Bhuyan, R., Lin, E. C., \& Ricci, P. F. (2010). Asian stock markets and the severe acute respiratory syndrome (SARS) epidemic: Implications for health risk management. International Journal of Environment and Health, 4(1), 1-40. https://doi.org/10.1504/IJENVH.2010.033033

Bollerslev, T. (1986). Generalized autoregressive conditional heteroskedasticity. Journal of Econometrics, 31(3), 307-327. https://doi.org/10.1016/0304-4076(86)90063-1

Caporale, G. M., You, K., \& Chen, L. (2019). Global and regional stock market integration in Asia: A panel convergence approach. International Review of Financial Analysis, 65. https://doi.org/10.1016/j.irfa.2019.101381

Celik, S. (2012). The more contagion effect on emerging markets: The evidence of DCC-GARCH model. Economic Modelling, 29(5), 1946-1959. https://doi.org/10.1016/j.econmod.2012.06.011

Corbet, S., Larkin, C., \& Lucey, B. (2020). The contagion effects of the COVID-19 pandemic: Evidence from gold and cryptocurrencies. Finance Research Letters, 35, 101554. https://doi.org/10.1016/j.frl.2020.101554

Dewandaru, G., Masih, R., \& Masih, M. (2018). Unraveling the Financial Contagion in European Stock Markets During Financial Crises: Multi-Timescale Analysis. Emerging Markets Finance and Trade, 54(4), 859-880. https://doi.org/10.1080/1540496X.2016.1266614

Dhanaraj, S., Gopalaswamy, A. K., \& Babu M, S. (2013). Dynamic interdependence between US and Asian markets: An empirical study. Journal of Financial Economic Policy, 5(2), 220237. https://doi.org/10.1108/17576381311329670 
Embrechts, P., McNeil, A. J., \& Straumann, D. (2010). Correlation and Dependence in Risk Management: Properties and Pitfalls. In Risk Management (pp.176-223). https://doi.org/10.1017/cbo9780511615337.008

Engle, R. (2002). Dynamic conditional correlation - a simple class of multivariate garch models. Journal of Business and Economic Statistics, 20(3), 339-350.

Errunza, V. R. (1977). Gains from Portfolio Diversification into Less Developed Countries' Securities: A Reply. Journal of International Business $\quad$ Studies, 8(2), 83-99. https://doi.org/10.1057/palgrave.jibs.8490875

Forbes, K. J., \& Rigobon, R. (2002). No contagion, only interdependence: Measuring stock market comovements. Journal of Finance, 57(5), 2223-2261. https://doi.org/10.1111/0022-1082.00494

Grubel, H. G. (1968). Internationally Diversified Portfolios: Welfare Gains and Capital Flows. American Economic Review, 58(5), 1299-1314. https://www.jstor.org/stable/1814029

Günay, S. (2020). A New Form of Financial Contagion: Covid-19 And Stock Market Responses. https://doi.org/10.13140/RG.2.2.24444.08325

Harris, R. D. F., \& Pisedtasalasai, A. (2006). Return and Volatility Spillovers Between Large and Small Stocks in the UK. Journal of Business Finance \& Accounting, 33, 1556-1571. https://doi.org/10.1111/j.1468-5957.2006.00635.x

Hoang Thuy Bich Nguyen, T., \& Huynh Lam, A. (2017). Financial Development, International Trade, and Stock Market Integration: Evidence in Six Southeastern Asia Countries. Journal of Economics and Development, 19(3), 5-17. https://doi.org/10.33301/jed.2017.19.03.01

Jiang, Y., Yu, M., \& Hashmi, S. M. (2017). The financial crisis and co-movement of global stock markets-a case of six major economies. Sustainability, 9(2), 260. https://doi.org/10.3390/su9020260

Kao, Y.-S., Zhao, K., Ku, Y.-C., \& Nieh, C.-C. (2019). The asymmetric contagion effect from the U.S. stock market around the subprime crisis between 2007 and 2010. Economic Research-Ekonomska Istraživanja, 32(1), 2422-2454. https://doi.org/10.1080/1331677X.2019.1645710

Karim, B. A., \& Majid, M. S. A. (2010). Does trade matter for stock market integration? Studies in Economics and Finance, 27(1), 47-66. https://doi.org/10.1108/10867371011022975

Karim, M. zaini, \& Gee, C. S. (2006). Stock Market Integration Between Malaysia and Its Major Trading Partners. Applied Econometrics and International Development, 6(3).

Karolyi, G. A. (1995). A multivariate GARCH model of international transmissions of stock returns and volatility: The case of the United States and Canada. Journal of Business and Economic Statistics, 13(1), 11-25. https://doi.org/10.1080/07350015.1995.10524575

Kim, B. H., Kim, H., \& Lee, B. S. (2015). Spillover effects of the U.S. financial crisis on financial markets in emerging Asian countries. International Review of Economics and Finance, 39, 192-210. https://doi.org/10.1016/j.iref.2015.04.005

Levy, H., \& Sarnat, M. (1970). International diversification of investment portfolios. The American Economic Review, 60(4), 668-675. https://www.jstor.org/stable/1818410

Mobarek, A., \& Mollah, S. (2016). Global Stock Market Integration: Co-Movement, Crises, and Efficiency in Developed and Emerging Markets. In Global Stock Market Integration: Co-Movement, Crises, and Efficiency in Developed and Emerging Markets. https://doi.org/10.1057/9781137367549

Naoui, K. N. (2010). A Dynamic Conditional Correlation Analysis of Financial Contagion: The Case of the Subprime Credit Crisis. International Journal of Economics and Finance, 2(3), 85-96. https://doi.org/10.5539/ijef.v2n3p85

Paramati, S. R., Gupta, R., \& Hui, A. (2016). Trade and Investment Linkages and Stock Market Long-Run Relationship. Australian Economic Papers, 55(2), 149-169. https://doi.org/10.1111/1467-8454.12066

Paramati, S. R., Roca, E., \& Gupta, R. (2016). Economic integration and stock market dynamic linkages: Evidence in the context of Australia and Asia. Applied Economics, 48(44), 4210-4226. https://doi.org/10.1080/00036846.2016.1153794

Sharpe, W. F. (1964). Capital Asset Prices: A Theory of Market Equilibrium under Conditions of Risk. The Journal of Finance, 19(3), 425-442. https://doi.org/10.2307/2977928

Solnik, B. H. (1977). Testing International Asset Pricing: Some Pessimistic Views. The Journal of Finance, 32(2), 503-512. https://doi.org/10.2307/2326783 
Vithessonthi, C., \& Kumarasinghe, S. (2016). Financial development, international trade integration, and stock market integration: Evidence from Asia. Journal of Multinational Financial Management, 35(C), 79-92. https://doi.org/10.1016/j.mulfin.2016.03.001

Vo, X. V. (2018). Trade Integration And International Financial Integration: Evidence From Asia. Singapore Economic Review, 1-12. https://doi.org/10.1142/S0217590818500248

WHO. (2020). WHO extends support to Pakistan as it confirms its first two cases of COVID-19.

WHO. (2021). WHO Coronavirus Disease (COVID-19) Dashboard. In World Health Oeganization.

Workman, D. (2020). Pakistan's Top Trading Partners. World's Top Exports.

Xiao, L., \& Dhesi, G. (2010). Volatility spillover and time-varying conditional correlation between the European and US stock markets. Global Economy and Finance Journal, 3(2), 148-164.

Yiu, M. S., Ho, W. Y. A., \& Choi, D. F. (2010). Dynamic correlation analysis of financial contagion in Asian markets in global financial turmoil. Applied Financial Economics, 20(4), 345-354. https://doi.org/10.1080/09603100903494946.
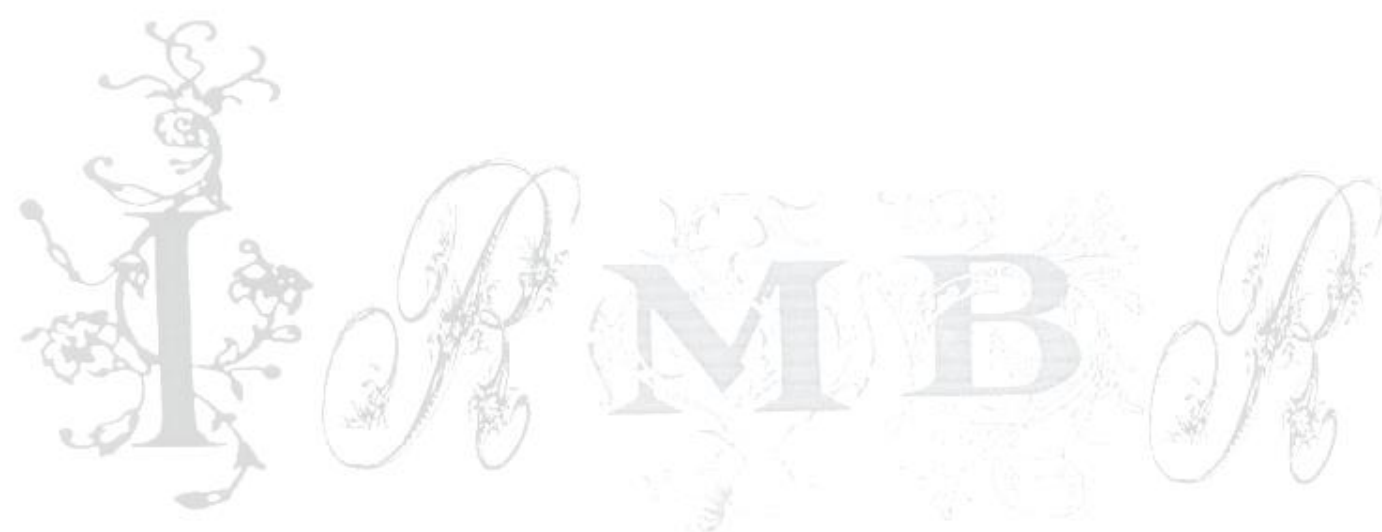